\title{
Spinal cord injury without radiographic abnormality
}

\author{
Anil P. Singh, Saswata Bharati, Shehbaz Ahmed, Laldhar Mishra, Dinesh K. Singh
}

Spinal cord injury without radiological abnormality is rare in adults. Below we present a case report of 20 yrs old male with isolated cervical cord injury, without accompanying vertebral dislocation or fracture involving the spinal canal rim. He fell down on plain and smooth ground while carrying $40 \mathrm{~kg}$ weight overhead and developed quadriparesis with difficulty in respiration. Plain radiographs of the neck revealed no fractures or dislocations. MRI showed bulky spinal cord and an abnormal hyper intense signal on the T2W image from C2 vertebral body level to C3/4 intervertebral disc level predominantly in the anterior aspect of the cord The patient was managed conservatively with head halter traction and invasive ventilatory support for the initial 7 days period in the ICU. In our patient recovery was good and most of the neurological deficit improved over 4 weeks with conservative management.

Key words: Spinal cord injury without radiological abnormality, spinal cord concussion

Spinal cord injury without radiological abnormality (SCIWORA) is a syndrome of post traumatic myelopathy without evidence of vertebral fracture or mal-alignment on plain radiographs or on computed tomography. This injury has been documented in children, probably due to increased elasticity of the paediatric spine. It has not been described very well in adults with normal spinal canals, although the elderly patients with osteoarthrotic spines and stenosed cervical canals can suffer traumatic spinal cord damage without accompanying vertebral injury. Below we present a case report of a $20 \mathrm{yrs}$ old male with isolated cervical cord injury, without accompanying vertebral dislocation or fracture involving the spinal canal rim.

\section{Case Report}

A 20 year old boy fell down on plain and smooth ground

\section{From:}

Department of Anaesthesiology, Institute of Medical Sciences, Banaras Hindu University, Varanasi, Uttar Pradesh, India

Correspondence:

Anil P Singh, Department of Anaesthesiology, Institute of Medical Sciences, Banaras Hindu University, Varanasi - 221 005, Uttar Pradesh, India.

E-mail: apsingh_net@sify.com while carrying $40 \mathrm{~kg}$ weight overhead, stood up without any discomfort and carried the same weight over head for around another $\mathbf{2 0 0}$ meters without any difficulty. After about four hours he noticed weakness in upper limb which was ignored by him. By the next morning ( 10 hrs) the weakness gradually progressed to involve both the lower limbs. There was no history of bowel and bladder involvement. There was no past history of any neurological disorder in this patient. He was brought to hospital and admitted in the emergency department. Few hours later he developed respiratory distress and was shifted to intensive care unit (ICU) for respiratory muscle weakness leading to inadequate tidal volume. On neurological examination, the sensory involvement was limited to loss of fine touch in all the four limbs and trunk. Motor examination showed normal muscle tone in all the four limbs. The muscle power of upper two limbs was grade 2/5 (MRC grade). Triceps jerk and supinator jerks were absent. Biceps jerk was present. In the lower limbs the muscle power was grade $3 / 5$ bilaterally. Knee jerk was present bilaterally but ankle jerk was absent. Cardiovascular system, respiratory system and per abdominal examinations were found to be within normal 
limits. There was no evidence of musculo-skeletal injuries. The patient was conscious and on arrival at the ICU his $\mathrm{BP}$ was $120 / 70 \mathrm{~mm} \mathrm{Hg}$, pulse rate $90 / \mathrm{min}$, regular in rhythm with normal volume. Respiratory rate was 30/ min with strenuous breathing pattern involving accessory respiratory muscles and the saturation $\left(\mathrm{SpO}_{2}\right)$ was $88 \%$ with $50 \% \mathrm{FiO}_{2}$. Arterial blood gas analysis revealed $\mathrm{pCO}_{2}-$ $50 \mathrm{mmHg}, \mathrm{pO}_{2}-56 \mathrm{mmHg}, \mathrm{pH}-7.28$ and $\mathrm{HCO}_{3}-22.1 \mathrm{mmol} /$ /L. His complete hemogram, serum electrolytes, creatinine, urea, coagulation profile, liver function tests were within normal limits.

\section{Imaging}

Cervical spine X-rays (AP and lateral views) showed no bony injury. MRI showed a bulky spinal cord and an abnormal hyper intense signal on the T2 weighted (T2W) imaging from $\mathrm{C}_{2}$ vertebral body level to $\mathrm{C}_{3 / 4}$ intervertebral disc level predominantly in the anterior aspect of the cord [Figures 1 and 2]. The features were suggestive of cord

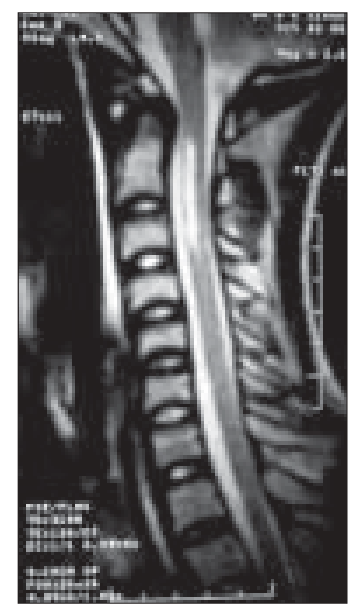

Figure 1: MRI plate showing the lesion in the cervical spinal cord

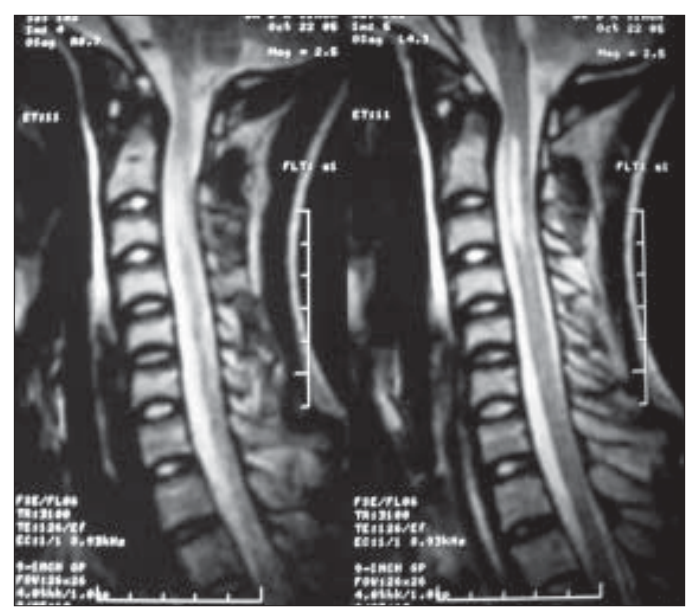

Figure 2: MRI plate showing the lesion in the cervical spinal cord in two sections contusion with cord oedema, without any vertebral abnormality.

\section{Management}

The patient was managed conservatively with head halter traction and invasive ventilatory support for the initial 7 days in the ICU with maintenance of normoxia, normocarbia, euglycemia, normovolemia and normal electrolytes. Patient received DVT prophylaxis, bowel bladder and back care, passive limb physiotherapy and enteral feeding with naso-gastric tube along with ventilatory support. He was weaned from ventilatory support successfully on $7^{\text {th }}$ day and stayed in ICU for another 11 days till the weakness in his limbs improved satisfactorily and the patient maintained a $\mathrm{SpO}_{2}$ more than $90 \%$ at room air. The patient was shifted to ward on the $18^{\text {th }}$ day and was discharged from the hospital on the $30^{\text {th }}$ day of admission. At the time of discharge the patient improved neurologically with improvement in muscle power (grade 4/5 in the upper limbs and grade $5 / 5$ in lower limbs) and return of triceps, supinator and ankle jerks. During the hospital stay the patient maintained blood pressure and pulse rate within normal limits.

\section{Discussion}

Cervical spinal cord can rarely be injured without a concomitant injury to either discocorporeal or discoligamentous structures. Such an injury is described in children, in whom the cervical spine has increased range of movements, including hyperflexion, hyperextension and distraction. Pang and Wilberger ${ }^{[1]}$ coined the term SCIWORA to distinguish this injury from traumatic myelopathy with disruption of skeletal elements of the cervical spine. SCIWORA is common among younger children specially aged 8 years or younger ${ }^{[2,3]}$ and uncommon in adolescents and adults though NEXUS, a large prospective multicenter observational study of 34,069 patients (3065 children), identified 818 spinal injuries (30 in children) where no case of SCIWORA was reported in any child although 22 cases were reported in adults. ${ }^{[4]}$

Spinal cord is a viscoelastic tissue exhibiting adaptive properties following stretch or compression of the cord. Equally important is the reciprocal behavioral adaptation of the meninges to neutralise the stretching of the cord. The osteoligamentous sheath represented by the spinal 
canal is deformable in normal mechanics of movement. The movements are thus naturally and passively sustained by the spinal cord and nerve roots. During non physiological movements of excessive amplitudes, the nervous structures can be subjected to strain which exceeds their capacity to adapt. It is thus likely that SCIWORA represents those cases where the force was sufficient to cause cord damage but was unable to damage the discocorporeal or discoligamentous structures. The injury is predominantly documented in children, probably due to an increased elasticity of pediatric spine. A young child's vertebral column can withstand elongation without any evidence of deformity while the spinal cord is injured. This mismatch of elasticity between the spinal column and spinal cord is the major factor contributing to the high incidence of SCIWORA injuries in young children. Upper cervical spine injuries typically involve young children more than adolescents. ${ }^{[3]}$ It appears that strain of the cervical spine in any direction can injure the cord. It has also been documented in thoracic spinal levels. ${ }^{[3]}$

Hyperflexion causes the maximum stretching of the cord. ${ }^{[5]}$ Prolonged neck flexion under anaesthesia or in cases of cervical spinal cord injury, acute hyperflexion may also result in impairment of blood flow to the cord. Tethering of the cord by the dentate ligament further worsens the condition. ${ }^{[6]}$ Hyperextension of the neck can damage the cervical cord. ${ }^{[7]}$ Greatest cord compression occurs between C3 and C6 due to pinching of the cord between the ligamentum flavum and posterior longitudinal ligament. ${ }^{[8]}$ Rotatory acceleration may result in spinal cord damage in a way similar to diffuse axonal injury in the brain. As shearing forces are generated in the spinal cord where the piamater is restrained more than the rest of the cord by the dentate ligament and spinal nerve roots, grey matter in the spinal cord gets damaged by rotatory acceleration. ${ }^{[9]}$

Spinal cord can be damaged due to the primary mechanical injury to the axons and microvasculature and a secondary injury, resulting from additional damaging processes initiated by the primary injury. ${ }^{[10]}$ Secondary cord injury occurs due to thrombosis, platelet aggregation or vasospasm of arterioles traversing the grey matter to supply the white matter. ${ }^{[11]}$ The ischaemic insult is further compounded by impairment of auto-regulation in the injured spinal cord, especially in the presence of systemic hypotension. ${ }^{[12]}$

The cervical spine radiographs usually do not show any abnormality. Flexion and extension views are essential to exclude instability. MRI demonstrated five classes of post-SCIWORA cord findings: complete transaction, major haemorrhage, minor haemorrhage, oedema only and normal. ${ }^{[13]}$ Cord oedema is the most common finding. MRI is used not only to image the injured cord, but also to prognosticate the outcome. ${ }^{[14-16]}$ Normal looking cord had the best prognosis; the outcome progressively worsened with the finding of intramedullary oedema involving one or more segment of cord segment and was worst with intramedullary haemorrhage. Patients with normal MRI may have features of mild cord dysfunction, which usually recovers within a short period. This condition is described as spinal cord concussion (SCC). It was hypothesized that SCC occurred due to functional disturbances of axonal membrane without disruption of structural integrity. ${ }^{[9]}$

Delayed onset of SCIWORA in children, has been documented. A delayed onset of neurological deficits may predispose to a worse outcome. SCIWORA injury is often at increased risk for recurrence. ${ }^{[3]}$

Management of spinal cord injury without associated fracture or dislocation is essentially conservative. Strict guidelines regarding treatment of this injury are lacking and there is significant variability between physicians regarding the type of treatment modality. External immobilization for 12 weeks helps patients who are moderately injured and also helps in preventing recurrences of these types of injuries. Many centers maintain patients in external braces such as a stiff cervical collar for several months in order to prevent further injury. The utility of high-dose methylprednisolone infusion within $8 \mathrm{~h}$ following acute spinal cord injury is controversial. Khandelwal, et a ${ }^{\left[{ }^{17]}\right.}$ showed improvement in neurological outcome in 9 out of 12 patients suffering from SCIWORA. Injury prevention, prompt recognition, use of MRI and timely bracing of patients with SCIWORA remain the chief measures to improve outcome. Prognosis of patients with SCIWORA is better when compared to the patients with spinal cord injury with bony injury. ${ }^{[17]}$ In our patient recovery was good and most of the neurological deficit improved over 4 weeks with conservative management. 


\section{Conclusion}

SCIWORA occurs more commonly in adults than previously thought. It appears that strain of the cervical spine in any direction can injure the cord. In hyperextension, the cord gets damaged due to compression, while in hyperflexion, rotatory acceleration and distraction, injury occurs due to a combination of stretching, tethering and vascular compromise. Management is conservative and outcome is not as grave as seen in injuries with cervical fracture or dislocations.

\section{Acknowledgements}

Intensive Care Unit, Department of Anaesthesiology, S.S Hospital, B.H.U. and Department of Orthopaedics, S.S Hospital, B.H.U.

\section{References}

1. Pang D, Wilberger JE Jr. Spinal cord injury without radiographic abnormalities in children. J Neurosurg 1982;57:114-21.

2. Osenbach RK, Menezes AH. Spinal cord injury without radiographic abnormality in children. Pediatr Neurosci 1989;15:168-75.

3. Pang D, Pollack IF. Spinal cord injury without radiographic abnormality in children - The SCIWORA syndrome. J Trauma 1989;29:654-64.

4. Viccellio P, Simon H, Pressman BD, Shah MN, Mower WR, Hoffman JR, for the NEXUS Group. A Prospective Multicenter Study of Cervical Spine Injury in Children. Pediatrics 2001;108:e20

5. Lyness SS, Wagman AD. Neurological deficits following cervical manipulation. Surg Neurol.1974;2:121-24.

6. Wilder BL. Hypothesis: The etiology of midcervical quadriplegia after operation with patient in the sitting position. Neurosurgery 1982;11:530-1.

7. Taylor AR, Blackwood W. Paraplegia in hyperextension cervical injuries with normal radiographic appearances. J Bone Joint Surg Am 1948;30B:245-9.

8. Taylor AR. The mechanism of injury to the spinal cord in the neck without damage to the vertebral column. J Bone Joint Surg Am 1951;33B:543-7.

9. Kobrine Al. The neuronal theory of experimental traumatic spinal cord dysfunction. Surg Neurol 1975;3:261-4.

10. Collins WF. A review and update of experimental and clinical studies of spinal cord injury. Paraplegia 1983;21:204-19.

11. Tator $\mathrm{CH}$, Fehlings MG. Review of the secondary injury theory of acute spinal cord trauma with emphasis on vascular mechanisms. J Neurosurg 1991;75:15-26.

12. Senter HJ, Venes JL. Loss of autoregulation and post traumatic ischaemia following experimental spinal cord injury. J Neurosurg 1979;50:198-216.

13. Pang D. Spinal cord injury without radiographic abnormality in Children, 2 decades later. Neurosurgery 2004;55:1325-43.

14. Marciello MA, Flanders AE, Herbison GJ, Schaefer DM, Friedman DP, Lane JI. Magnetic resonance imaging related to neurologic outcome in cervical spinal cord injury. Arch Phys Med Rehabi 1993;74:940-6.

15. Kulkarni MV, McArdle CB, Kopanicky D, Miner M, Cotler HB, Lee $\mathrm{KF}$, Harris JH. Acute spinal cord injury. MR imaging at $1.5 \mathrm{~T}$. Radiology 1987; 164:837-43.

16. Schaefer DM, Flanders AE, Osterholm JL, Northrup BE. Prognostic significance of magnetic resonance imaging in the acute phase of cervical spine injury. J Neurosurg 1992;76:218-23.

17. Khandelwal S, Sharma GL, Saxena UD, Sakhi P, Gopal S, Saxena P. Prospective evaluation of cervical spine injuries by MRI and assessing role of MR findings in predicting prognosis. Ind J Radiol Imaging 2004;14:71-80.

Source of Support: Nil, Conflict of Interest: None declared. 